\title{
Procedimientos de control y registro contable bajo NIC SP para los activos del Gobierno Autónomo Descentralizado Parroquial de Fundochamba de la provincia de Loja
}

Control procedures and accounting record under IASPS for the Autonomous Decentralized Parochial Government of Fundochamba in the province of Loja.

Glenda Mavel Lozano Calero. ${ }^{1}$, Cecilia Ivonne Narváez Zurita. ${ }^{2}$, Juan Carlos Erazo Álvarez. ${ }^{3} \&$ Myriam Alejandra Montero Cobo. ${ }^{4}$

DOI: https://doi.org/10.33262/visionariodigital.v3i2.1.582

\begin{abstract}
Currently a number of Autonomous Decentralized Governments of Ecuador are elaborating their financial statements on the basis of the International Accounting Standards that apply to the Public Sector (IASPS), since the information contained is considered very useful to stablish the responsibility parameters and to make decisions. In this regard, the financial statements prepared according to the IASPS allows users to evaluate the financial resource management, financial position, performance and cash flows of public entities.

Faced with this scenario, it was considered to be relevant to analyze the parameters under which the financial states of the Autonomous Decentralized Parochial Government of Fundochamba; located in the canton of Quilanga in the province of Loja, are being prepared. Since, the current crisis that Ecuador is facing and the fiscal restraint that are feeling all over the country, it is considered to be relevant that this institution reports in a transparent manner its accounts handled. Under those circumstances, as results of this research that was developed under a mixed approach and with descriptive - explicative scope, it was stablish that the ADG under
\end{abstract}

\footnotetext{
${ }^{1}$ Universidad Católica de Cuenca, Posgradista Maestría en Contabilidad y Auditoría, Cuenca, Ecuador, glozanoc@psg.ucacue.edu.ec

2 Universidad Católica de Cuenca, Posgrados, Cuenca, Ecuador. inarvaez@ucacue.edu.ec

${ }^{3}$ Universidad Católica de Cuenca, Posgrados, Cuenca, Ecuador. jcerazo@ucacue.edu.ec

${ }^{4}$ Universidad Católica de Cuenca, Posgrados, Cuenca, Ecuador. miriam.monteros@ucacue.edu.ec
} 
consideration presents difficulties in: the use of accounts handled, the application of accrual-based principle, the account handled maintenance and budget headings. The identified issues motivated to the development of a control of procedures manual and the asset account register on the basis of the IASPS, in particular for the purpose of improving the quality, the consistency and the comparability of the financial statements in the institution.

Keywords: control procedures, financial information, assets, public entities.

\section{Resumen}

En la actualidad un número de Gobiernos Autónomos Descentralizados del Ecuador están elaborando sus estados financieros sobre la base de las Normas Internacionales de Contabilidad aplicables al Sector Público (NICSP), ya que la información que contienen los mismos, es considerada de gran utilidad para establecer los parámetros de responsabilidad y para fines de toma de decisiones, en este sentido, los reportes financieros elaborados en concordancia con las NICSP permiten a sus usuarios valorar la gestión de los recursos económicos, la posición financiera, desempeño y flujos de efectivo de las entidades públicas.

Ante este escenario, se consideró pertinente analizar los parámetros bajo los cuales se están elaborando los estados financieros del Gobierno Autónomo Descentralizado Parroquial de Fundochamba, localizado en el cantón Quilanga, provincia de Loja, ya que, a partir de la crisis actual que atraviesa Ecuador y las restricciones fiscales que se están sintiendo en el país, se considera necesario que esta institución reporte de manera transparente sus cuentas contables. En tal virtud, como resultados de esta investigación que se desarrolló bajo un enfoque mixto y con alcance descriptivo explicativo, se estableció que el GAD en estudio presenta dificultades en: la utilización de las cuentas contables, la aplicación del principio de devengo, la actualización de cuentas contables y partidas presupuestarias. Los problemas identificados motivaron a la elaboración de un manual de procedimientos de control y registro de las cuentas del activo sobre la base de las NICSP, con la finalidad de mejorar la calidad, la consistencia y la comparabilidad de los estados financieros de la institución.

Palabras claves: procedimientos de control, información financiera, activos, entidades públicas.

\section{Introducción.}

En el Ecuador, mediante Registro Oficial No. 303 del 19 de octubre de 2010 se reconoce como Ley de la República el Código Orgánico de Organización Territorial, Autonomía y 
Descentralización (COOTAD) en el cual se da personería jurídica a los Gobiernos Autónomos Descentralizados Parroquiales Rurales (GADPR), quienes se encargan de administrar fondos públicos, expedir acuerdos, resoluciones y normativas reglamentarias en las materias de competencias exclusivas determinadas en el mismo cuerpo legal.

Para la administración de fondos públicos los GADPR deben regirse a las diferentes leyes, reglamentos y normas establecidas por los entes reguladores del sector público, considerando que actualmente para el registro y control de la información financiera se utilizan de manera empírica los procedimientos contables basados en el principio general de partida doble y devengado, puesto que aún no se han implementado las normas de contabilidad gubernamental existentes.

La Contabilidad Gubernamental (CG) se define como el procedimiento de registrar sistemáticamente, en forma cronológica y en orden, los movimientos económicos de las entidades que pertenecen al Estado, desde el registro original contable, con base en el devengado hasta la revelación de los informes contables obtenidos al finalizar el periodo fiscal; además, contribuye a determinar la situación económica del patrimonio público (Ministerio de Economía y Finanzas, 2017).

La Ley Orgánica de la Contraloría General del Estado (LOCGE) en su artículo 13 señala a la CG como un medio para controlar a los organismos públicos, creada con el objetivo de facilitar el manejo de la información financiera mediante sistemas informáticos contables únicos que registran la ejecución del presupuesto así como su incidencia en el patrimonio, y que se ven reflejados en los estados financieros y sirven como documentos soporte para tomar decisiones administrativas en beneficio de la colectividad (Contraloría General del Estado, 2002).

Para el inicio del proceso de CG es necesario contar con la respectiva documentación que soporte las transacciones y movimientos diarios, que serán analizados previo al registro de los hechos económicos en la etapa de ejecución, para finalizar en la consolidación de los estados financieros que transparentan el uso de los recursos públicos para entendimiento de los usuarios finales. Este proceso debe estar basado en normas de contabilidad que regulan la correcta aplicación de las disposiciones legales vigentes.

Para el registro de las transacciones se debe tomar en consideración el principio del devengado que son los ingresos y salidas que se registran en el momento en que acontece el intercambio de los fondos económicos por bienes o servicios adquiridos; así también, el principio de asociación contable presupuestaria que registra los movimientos de ingresos y salidas que se realicen en cada una de las cuentas determinadas en el clasificador presupuestario; de la misma manera se debe considerar el principio de medición económica, que da referencia a que todo movimiento económico que realice la institución gubernamental 
debe de expresarla en la moneda que se encuentra legalmente circulando en el país y por último el principio del hecho económico, que hace referencia a las operaciones mercantiles, operativas o financieras que tienen su origen en el momento en que se intercambia un bien, producto o servicio por otro o su equivalente en dinero.

La CG como su nombre lo indica, se aplica en las instituciones que se financian con fondos del Estado, razón por la cual su evaluación es una obligación para determinar si la gestión emprendida por las autoridades ha sido pertinente, esto se plasma en la consolidación de los estados financieros y reportes contables que se emiten periódicamente a los entes de control pertinentes, Díaz (2010) manifiesta que los mismos deben estar estructurados de acuerdo a las disposiciones legales vigentes y a la normativa internacional adoptada, en el caso de la entidades del gobierno, los Estados financieros tienen la misma función y permiten a los directivos llegar a conclusiones sobre su gestión que posteriormente será evaluada por los organismos de control, principalmente por la Contraloría General del Estado, entidad encargada de velar por el correcto manejo de los recursos públicos.

La norma internacional de contabilidad (NIC) 1 señala en su parte pertinente que el objetivo de los estados financieros es reflejar en ellos la posición financiera de la entidad, que sean comprensibles de forma general para quienes dispongan de ellos y que a partir de sus resultados se tomen decisiones adecuadas (Perea, Castellanos y Valderrama, 2016). Al respeto, Medina y Morocho (2015) clasifican a los usuarios de la información financiera en internos y externos; entre los internos, se tiene a los dignatarios que son los que están al frente de los recursos de cada entidad pública y por consiguiente requieren de la información para tomar sus decisiones y los servidores públicos, para conocer el pago de sus remuneraciones; entre los externos, están el gobierno nacional, que necesita determinar el patrimonio de cada entidad que recibe fondos del Estado; la Función Legislativa cuya función es legislar y por lo tanto, requiere de información para dar inicio a sus funciones encomendadas; contratistas del Estado, que son los proveedores de bienes y servicios que necesitan conocer si existen los fondos necesarios para su cancelación, y organismos de control; principalmente la Contraloría General del Estado que realiza auditorias financieras en el caso del Ecuador.

Los estados financieros son todos aquellos que presentan la situación real del ente, los resultados de las operaciones, los cambios en el patrimonio y en la situación financiera, así como los flujos de efectivo, de tal manera se clasifican en los siguientes:

Estado de resultados. - Muestra los ingresos y gastos en los que incurre la entidad durante el periodo contable, se su relación, ingresos menos gastos se obtiene la utilidad o pérdida del ejercicio correspondiente (Ortíz, 2008). 
Estado de situación financiera. - Es un Estado financiero estático, es decir muestra la situación patrimonial de la empresa en un momento específico, presenta la situación de los activos, pasivos y el patrimonio (Aguirre, 2010).

Activos. - Son los bienes y derechos de la entidad, independientemente de cómo han sido financiados, dentro de este grupo se tiene los siguientes subgrupos adicionales; activos corrientes que son todos los recursos que representan liquides o aquellas partidas que se espera se conviertan en dinero en un plazo no mayor a los doce meses (Bravo, 2011).

Activos no corrientes que son aquellos rubros que contribuyen o coadyuvan en la ejecución de las obras o servicios que presta la institución, aquí es precisamente donde intervienen las propiedades planta y equipos o activos fijos, que generalmente representan un valor considerable al ser necesarios en todas las operaciones del gobierno (Aguirre, 2010).

Considerando que el presente trabajo investigativo centra su atención en el grupo de los activos, se detalla los grupos de cuentas objeto de análisis:

- Disponibilidades, incluye las cuentas cuyos saldos se efectivizan en corto plazo, rubros para fines especiales, títulos emitidos por el Estado e inversiones de corto plazo que no han sido contempladas en la planificación presupuestaria.

- Anticipos de fondos, da tratamiento a las cuentas que incluyen los anticipos otorgados a servidores, contratistas y proveedores, cauciones, fondos a rendir cuentas, adeudos indebidos pendientes de recuperación.

- Cuentas por cobrar, son los derechos a favor de la entidad.

- Bienes de administración, controla el movimiento de las cuentas de muebles e inmuebles cuyo uso es exclusivo para las actividades u operaciones de la institución.

- Deudores financieros, comprende las cuentas que reflejan saldos a favor de la entidad pero que no se les da tratamiento en los grupos anteriores.

- Inversiones diferidas, registran los valores por los servicios que se devengan con su adquisición y que se amortizan de acuerdo a su consumo al final del periodo contable, por lo general al 31 de diciembre de cada año.

- Inversiones en obras en proceso, Acumulan las cuentas que intervienen en el registro contable sobre la edificación de obras, mejoras o mantenimiento de infraestructura, complementos, sus similares o derivados, y que netamente se encaminan a mejorar la calidad de vida de la comunidad (Ministerio de Economía y Finanzas, 2017, p.1).

Pasivos son las obligaciones a corto o largo plazo que la entidad tiene con personas naturales o jurídicas, dentro de este grupo se tiene los siguientes subgrupos adicionales; pasivos corrientes, son las obligaciones que tiene la entidad y que deben ser cubiertas por la institución en un periodo no mayor a los doce meses posteriores a la fecha del compromiso (Chávez, Campuzano y Alvarado, 2015). 
Pasivos no corrientes son los compromisos que deben ser asumidos en un período mayor a los doce meses, generalmente son las deudas o financiamiento con las instituciones financieras.

El Patrimonio es la relación entre los activos y pasivos, es el capital propio de la entidad, y patrimonio público es el que comprende los movimientos del financiamiento propio.

Otro estado esencial es el estado de flujo de efectivo que presenta en forma condensada y comprensible la información sobre el manejo del efectivo por parte de la entidad, durante un periodo determinado, y por lo tanto muestra la síntesis de los cambios ocurridos en la situación financiera, o sea en sus inversiones y financiamiento (Romero, 2000).

Y finalmente el Estado de ejecución presupuestaria que será preparado con el conjunto de partidas determinadas en el clasificador presupuestario y no con las partidas de detalle, las mismas que demuestran su comportamiento en el período (Medina y Morocho, 2015).

Es necesario contar con normas que regulen los procedimientos contables, así como la presentación de los estados financieros con énfasis en obtener una información estandarizada, fiable y oportuna, por ello el Consejo de Normas Internacionales de Contabilidad del Sector Público (International Public Sector Accounting Standards Board/IPSASB) de la Federación Internacional de Contadores acordó la creación de las Normas Internacionales de Contabilidad para el Sector Público (NICSP).

Las NICSP son el resultado de la unificación de las Normas Internacionales de Contabilidad (NIC) y las Normas Internacionales de Información Financiera (NIIIF) con el fin de reconocer, medir, cuantificar, indicar y revelar las operaciones y actividades económicas en los informes financieros de cada ente u organismo público, son aplicables a empresas públicas y su propósito es generar una estructura uniforme de la información contable que se maneja en este tipo de instituciones (Ablan, 2013). Esta normativa permite que las instituciones del sector público, puedan ejercer su registro contable en un marco internacional, haciendo posible su comparabilidad.

Las organizaciones internacionales que promulgan las NICSP, vienen recomendando a los gobiernos la implementación y aplicación de las normas para garantizar la transparencia de la información pública, y además garantizar las líneas de crédito por parte de entidades financieras a nivel mundial como el Fondo Monetario Internacional (FMI), que ya están exigiendo su armonización en todo tipo de entidades, sean públicas o privadas (Tombolato, 2014). Sánchez y Pincay (2013), señalan que las NICSP buscan de manera eficiente, armonizar la información económica bajo directrices del FMI, organismo que es miembro activo de la Federación Internacional de Contadores (IFAC) que conjuntamente con el IPSASB han publicado más de 32 normas para uso exclusivo de las entidades del sector público. Por su parte, Lamanttina (2012), indica que las NICSP son consideradas como el 
instrumento necesario para dar información confiable de la realidad financiera de las entidades gubernamentales, deben ser administradas eficientemente y desarrollar su importancia con el transcurrir de los periodos. La planificación y el control son dos actividades administrativas que siempre van iguales, para realizar un control eficaz es necesario plantear una planificación de las actividades, no tendría una razón de ser el efectuar una planificación de operaciones de la entidad si después no se va a realizar el respectivo control sobre dichas operaciones.

Si bien es cierto, las NICSP son una herramienta valiosa para la toma de decisiones, transparencia y comparabilidad, sin embargo, por sí solas no solucionan el problema de los países, sino que se requiere de un control interno eficaz para su verdadera armonización y puesta en práctica en los mejores términos de eficiencia y calidad.

En este contexto, el control interno (CI) se define ampliamente como el dinamismo que manifiesta si las actividades se encuentran realizadas según lo establecen los organismos de control para determinar la razonabilidad y confianza en los datos obtenidos, dicha actividad debe de ser realizada por los administradores, auditores o personal con conocimientos suficientes para que asegure que las actividades se encuentran bien efectuadas (Mantilla, 2005). Las operaciones deben realizarse con eficiencia y a la vez con eficacia con el fin de determinar si se están cumpliendo las metas propuestas en el ente, teniendo en cuenta la rentabilidad y la gestión realizada por los administradores para salvaguardar los bienes del Estado. El CI incluye controles que pueden ser tanto contables como administrativos, en ese sentido, se presenta la siguiente clasificación:

- Control interno financiero, es aquel que determina si la entidad se encuentra utilizando de forma eficiente los fondos y si los registros efectuados pertenecen a las actividades realizadas por el ente gubernamental, debe de verificar si los datos económicos presentados en los estados financieros son de absoluta confianza y razonables, comprobando si las operaciones se encuentran autorizadas por la autoridad competente y registrada bajo las normas aplicables para efectos del caso.

- Control interno administrativo, es el que se efectúa a la gestión administrativa para determinar si la organización mediante las decisiones superiores, está cumpliendo con la normativa vigente que conllevan a alcanzar los objetivos planteados por la entidad.

- Control interno previo, son aquellas actividades que se realizan antes de efectuar una operación económica o actividad administrativa con el fin de evitar desvíos económicos, están son aplicadas desde el administrador principal y a cada departamento para determinar la legalidad de cada actividad.

- Control interno concurrente, radica en el cumplimiento de cada una de las normas, políticas y procedimientos señalados para realizar el control con la finalidad de instaurar elementos necesarios que conlleven a los objetivos y metas que se determinaron al principio del examen con el fin de conocer si las actividades realizadas se encuentran acorde con los objetivos propuestos. 
- Control interno posterior, tiene como finalidad evaluar, examinar el cumplimiento de las recomendaciones efectuadas al finalizar la auditoria, dicha actividad puede ser efectuada por el departamento de auditoría interna y así asegurar que se dé absoluto acatamiento a las normas, leyes y demás disposiciones que determine la administración (Universidad Nacional de Loja, 2009, p. 17).

El CI determina si se está cumpliendo con las normas, políticas y demás leyes que rigen a las instituciones, debe de estar dirigido por individuos con conocimientos suficientes sobre el manejo de fondos, gestión administrativa y lo que indica los manuales de procedimientos y formularios que son realizados por la CGE, que hacen referencia a cada nivel o departamento de la entidad (Board y Junta Directiva, 2005). En tal razón, la utilización de manuales, guías o demás instructivos, es fundamental para que el talento humano de las instituciones públicas se desenvuelva de manera eficaz en cada una de las actividades asignadas, quedando a su disposición el procedimiento adecuado que debe utilizar en casos específicos y asegurando que la información contable presente de forma razonable la situación da la entidad en un momento determinado.

\section{Metodología}

Para el desarrollo de la presente investigación se utilizó una población de 7 personas subdividas en 5 directivos y dos operativos del GAD Parroquial de Fundochamba del cantón Quilanga, quienes brindaron información oportuna para el conocimiento de la realidad de la entidad y en función a ello brindar alternativas de solución ante lo dispuesto por el Ministerio de Finanzas de presentar información económica bajo normativa internacional.

El enfoque cualitativo de la investigación se centró en el estudio y desarrollo de las variables objeto de estudio y en el tratamiento de la fundamentación teórica, mientras que, el enfoque cuantitativo permitió realizar el tratamiento de la información recolectada a través de las encuestas, entrevistas y revisión documental. Su alcance fue descriptivo / explicativo en razón de que se describieron las variables de estudio, sus características y particularidades y se explicó cómo deben aplicarse los procedimientos de control y registro de las cuentas del activo. En cuanto a los métodos, el inductivo / deductivo permitió el análisis de la teoría contable gubernamental desde una perspectiva general y de las NICSP desde una perspectiva específica; el método histórico - lógico permitió plasmar las revisiones literarias en el desarrollo de la fundamentación teórica un orden lógico y cronológico.

\section{Resultados}

\section{Estado de situación financiera}

El estado de situación financiera corresponde a la presentación de los activos pasivos y patrimonio de forma ordenada, en una fecha específica, sirve para conocer el financiamiento 
de los activos y en base a ello tomar las decisiones que se consideren pertinentes; como resultado de la aplicación de los instrumentos de investigación se determinó que el registro contable de las actividades realizadas por el Gobierno Autónomo Descentralizado de la Parroquia Fundochamba, se efectúa en base a las Normas Técnicas de Contabilidad Gubernamental emitidas por el Ministerio de Economía y Finanzas, que tiene una base importante de lo que establecen las NICSP. Sin embargo, se determinó una mala utilización de las cuentas contables, así como de las partidas presupuestarias.

\section{Estado de resultados}

El estado de resultados permite apreciar los ingresos y gastos que se han efectuado en la entidad durante un ejercicio económico, su aplicación sirve para traspasar los resultados netos de la gestión al estado de situación financiera y sobre todo determinar que gastos son los que mayor flujo de efectivo generan; de los resultados obtenidos se puede evidenciar que el Gobierno Parroquial registra sus ingresos y gastos en el programa contable SIG - AME, no obstante, los hechos económicos o transacciones no han sido registrados bajo el principio del devengado conforme lo establece las NICSP, es decir no han sido registrados en la fecha en que ocurren sino solo hasta que se cumplió el pago respectivo, siendo una falta significativa que no permite determinar la razonabilidad de los saldos en los estados financieros.

\section{Estado de flujo del efectivo}

Este estado financiero muestra los usos y fuentes del dinero que la entidad ha manejado en el periodo económico, su función principal es informar sobre las principales entradas de dinero y sobre todo que gastos o inversiones demandan mayor inversión; en lo referente a este estado dentro del Gobierno Parroquial, se evidencia que el mayor movimiento de dinero es dentro de las cuentas de gastos, puesto que los ingresos son marcados por las transferencias del Ministerio de Finanzas de forma mensual y los ingresos por autogestión no superan el $3 \%$ del ingreso total. Adicionalmente es relevante destacar que en el periodo económico 2018 al mes de septiembre se cargó el estado de flujo del efectivo a la página del ESIGEF descuadrado, por lo que, el Ministerio de Economía y Finanzas notificó a la institución para que se realicen los ajustes necesarios y así poder consolidar la información.

\section{Estado de ejecución presupuestaria}

Es un estado específico del sector público, en el que detalla la relación entre lo presupuestado y lo que efectivamente se está ejecutando, tanto en gastos como en ingresos. La ejecución presupuestaria del Gobierno Parroquial, no presenta inconsistencias determinándose que éste estado tiene razonabilidad en sus cifras, esto debido a que la Plataforma del Ministerio de Finanzas sirve como control permanente; lo que es relevante mencionar es que los datos del presupuesto no han sido objeto de una evaluación oportuna para determinar la gestión eficaz de las autoridades para dar cumplimiento a sus programaciones anuales. 


\section{Notas aclaratorias}

Son descripciones de situaciones cuantitativas o cualitativas que permiten a los usuarios de la información contable comprender con mayor facilidad la información consolidada; dentro de los estados financieros no se evidencian notas aclaratorias que sustenten la información presentada, se omite su elaboración sin considerar que las mismas sirven de apoyo y facilitan la comprensión a los diferentes usuarios de la información financiera.

\section{Propuesta}

Las situaciones citadas en la fase de diagnóstico justifican el diseño de los procedimientos de control y registro contable, con la finalidad de garantizar una información financiera razonable bajo estándares internacionales de contabilidad aplicables al sector público:

Figura 1. Esquema de propuesta

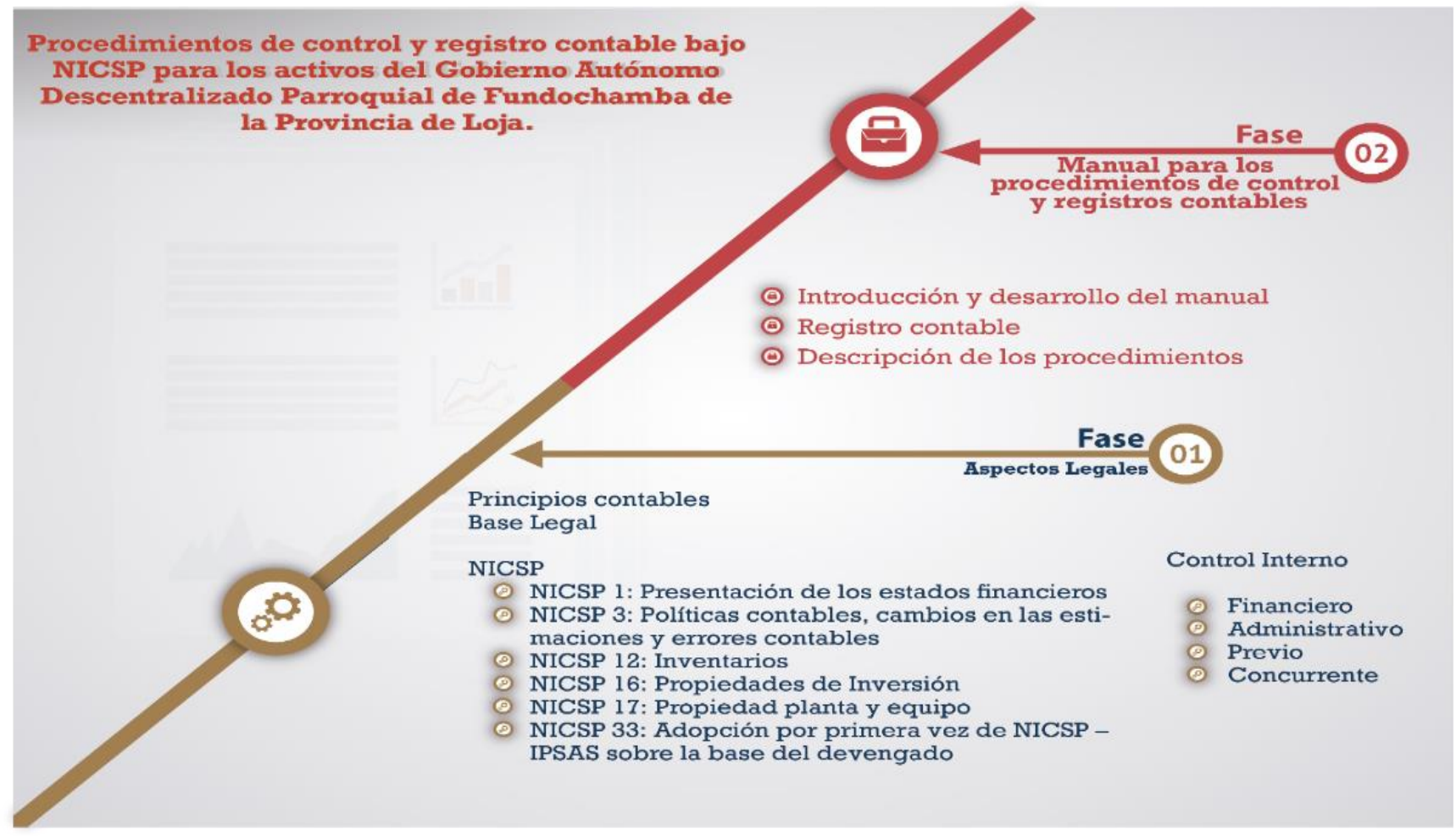

\section{Fase I}

\section{Aspectos legales}

El presente manual de procedimientos contables está elaborado bajo la aplicación de las Normas Internacionales de Contabilidad del Sector Público, Ley de Régimen Tributario 
Interno, Código Orgánico de Planificación y Finanzas Públicas, y Normas de Control Interno para el Sector Público.

\section{Definiciones}

- Activos: bienes y derechos de la entidad que se considera se efectivizaría en corto plazo su proporción corriente y a largo plazo los valores que constan en la parte que se determina no corriente.

- Balance de Comprobación: informe que contiene las partidas registradas en el libro mayor con indicación de sus saldos débitos y créditos.

- Conciliación Contable: documento que identifica las partidas en conciliación que ameritan un ajuste para hacerla coincidir con la realidad.

- Libro mayor: es un libro que recoge todas las operaciones económicas registradas en las distintas cuentas contables de la empresa de manera cronológica.

- Libro Diario: reconoce de forma ordenada las transacciones que ocurren cotidianamente, su estructura incluye fecha, detalle, referencia, columnas para valores parciales y saldos tanto deudores como acreedores.

- Soportes de contabilidad: Son la base de las operaciones de las entidades, es por ello que se debe tener cuidado al elaborar los registros y cuantas copias fueren necesarias según la necesidad de cada entidad.

- Aportes de capital: activos que han sido aportados por terceros.

- Base contable de acumulación o devengo: Método contable por medio del cual las transacciones y otros hechos económicos son reconocidos o registrados en el momento en que ocurren, y no necesariamente cuando incurre su recaudación o su desembolso. Los elementos que son reconocidos sobre el devengo son activos, pasivos, activos netos, patrimonio neto e ingresos o gastos ordinarios.

- Control: Potestad de dirigir las políticas financieras y de operación de otra entidad, beneficiándose de sus actividades.

- Moneda de estados financieros: Aborda la moneda que se utiliza para la presentación de los estados financieros, actualmente a Ecuador le corresponde en dólares, por ser su moneda oficial.

- Políticas contables: Estándares establecidos por cada entidad con la finalidad de que la información financiera se encuentre acorde a las disposiciones establecidas en todas las NICSP

\section{Responsabilidades}

Las responsabilidades para el estricto cumplimiento de los procedimientos son exclusivas de la máxima autoridad y de todo el personal que disponga de los recursos públicos, es decir, que sea parte de la entidad, ya que son los encargados de velar por el correcto manejo y uso 
de los fondos que disponen para el desarrollo de sus actividades inherentes, tal como lo establece la norma de control interno 100-01 de la CGE.

\section{Políticas contables}

- En el proceso de gestión contable del GADPF se obtiene información económica a partir de procedimientos contables, donde todas y cada una de las operaciones identificadas suministran la información contable que la institución requiere, en el tiempo oportuno y con las características que las normativas vigentes exigen.

- El proceso contable comprende varias etapas que contribuyen en la elaboración y consolidación de los EEFF, garantizando el adecuado cumplimiento de las características cualitativas del manual de procedimientos contables para el registro y control de los activos del GAPF. Cualquier situación que no se contemple en el manual, deberá ser consultada en el marco normativo que rige a las instituciones del sector público.

- El procedimiento contable reconoce y registra la información originada en las áreas funcionales, evidenciando la realidad financiera y económica del GADPF y representa dicha información a través de los instrumentos de partida doble, la base del devengado y posteriormente sintetiza y revela la situación financiera en el estado de resultados, estado de situación financiera, estado de flujo del efectivo y estado de ejecución presupuestaria.

- La contadora (contador) del GADPF, es la única persona responsable de la elaboración y presentación de los EEFF, de acuerdo con los parámetros establecidos por el Ministerio de Economía y Finanzas.

- Los controles asociados a los procedimientos contables corresponden a las acciones adoptadas a partir de las normas de control interno para el sector público, con la finalidad de mitigar los distintos riesgos que pueden incidir negativamente en la información contable.

- Los funcionarios que laboran en las distintas áreas administrativas y generan transacciones y operaciones susceptibles de ser reconocidas contablemente, son responsables de la operatividad eficiente del procedimiento contable desde la generación de la información hasta su oportuna entrega para la contabilización.

- La depreciación de un activo comenzará cuando esté disponible para su uso, esto es, cuando se encuentre en la ubicación y en las condiciones necesarias para operar de la forma prevista por la administración. 
Tabla 1. Aspectos legales en base a NICSP

\section{Principios Contables según NIC SP}

Negocio en Marcha

Uniformidad en la presentación

Importancia relativa y agrupación de datos

Compensación

Información comparativa

Periodo sobre el cual se informa

Oportunidad
Es la perspectiva de que la entidad donde se elaboran estados financieros según NICSP, continúe funcionando por un periodo de tiempo mayor a un año.

Se refiere a que la presentación y clasificación de las partidas en los estados financieros deben ser conservadas de un período a otro con el fin de ser compatibles para su estudio; con la excepción de que exista un cambio de las actividades relacionadas o se vea obligada a realizar cambios por la aparición de una NICSP que así lo disponga.

Las partidas presupuestarias que son importantes en cuanto a valores a su clasificación deberán presentar sus saldos de manera individual en los estados financieros; los conceptos materiales, pero de misma naturaleza podrán agruparse.

No se pueden compensar activos con pasivos, a menos que la compensación sea exigida o permitida en alguna NICSP; lo mismo sucede con las partidas de ingresos ordinarios y gastos.

La información de los estados financieros podrá ser comprada con la de años anteriores, ya que han sido procesados de la misma forma, a menos que una NICSP lo permita o exija otra cosa.

Los estados financieros se presentarán con una periodicidad mínima de un año.

Los datos de los estados financieros deben ser presentados a os diferentes usuarios en tiempo prudencial para la oportuna toma de decisiones.

\section{Fuente: NICSP 1}

Los Procedimientos de control y registro contable bajo NICSP para los activos del Gobierno Autónomo Descentralizado Parroquial de Fundochamba de la provincia de Loja, consideraran las siguientes normas: 
- NICSP 1: Presentación de los estados financieros

- NICSP 3: Políticas contables, cambios en las estimaciones y errores contables

- NICSP 12: Inventarios

- NICSP 16: Propiedades de Inversión

- NICSP 17: Propiedad planta y equipo

- NICSP 33: Adopción por primera vez de NICSP - IPSAS sobre la base del devengado

\section{Control interno}

Los procedimientos de control interno, su formulación, aplicación y perfeccionamiento son de exclusiva responsabilidad de la máxima autoridad y de todo el personal de cada entidad, con ello se logra que las actividades financieras, operativas y administrativas se realicen de tal forma que permitan el cumplimiento de las actividades programadas y metas propuestas, haciendo énfasis en la protección de los recursos públicos.

Es importante destacar que la máxima autoridad tiene la potestad de establecer tanto las líneas de conducta como las medidas de control interno en que se va incurrir para generar información razonable y lograr los objetivos institucionales, pudiendo realizar supervisiones y regulaciones en los procedimientos constantemente con la finalidad de medir la eficacia y calidad de los controles implementados.

\section{Fase II}

\section{Introducción}

Los procedimientos de control y registro contable bajo NICSP para los activos del Gobierno Autónomo Descentralizado Parroquial de Fundochamba de la provincia de Loja, son presentados como una alternativa para lograr la maximización de los recursos y alcanzar sus objetivos institucionales con eficiencia y en los tiempos establecidos; su aplicación también permite dar cumplimiento a la disposición del Ministerio de Economía y Finanzas que a partir de enero del 2020 las entidades públicas, excepto las del sector financiero, deben aplicar normativa internacional con el fin de garantizar información comparable con otras entidades del mundo y también las de fiabilidad, comprensibilidad y relevancia.

En su estructura, el usuario puede encontrar las políticas contables para cada elemento considerado en el manual, los procedimientos y el flujograma respectivo, de manera que contribuya a que entidades similares puedan procesar su información contable en base a normativa internacional, armonizando sus informes contables y presentar estados financieros de forma razonable. El objetivo que se persigue es contribuir al personal encargado del procesamiento de las operaciones de la entidad, sujeta a estudio, a establecer los procedimientos oportunos para optimizar los recursos y obtener los mayores beneficios con la menor inversión posible. 


\section{Objetivo}

Establecer y estandarizar lineamientos para el registro y control de las cuentas del activo, con la finalidad de garantizar que los estados financieros presenten información razonable y oportuna, evitando de esta manera las malas prácticas contables.

\section{Alcance}

El alcance del manual de procedimientos contables va desde la planeación, recepción, registro y control de la información relacionada con las cuentas de los activos, hasta la entrega de los estados financieros a los usuarios internos y organismos de control del Gobierno Autónomo Descentralizado Parroquial de Fundochamba.

\section{Descripción de los procedimientos contables para registro y control de los activos.}

\section{Procedimiento para registro y control de disponibilidades: transferencias.}

Se debe considerar lo siguiente:

a. El Departamento de contabilidad deberá en los tiempos establecidos remitir la contabilidad en la plataforma E-sigef del MEF.

b. Previo a su validación cada mes debe encontrarse cerrado.

c. Una vez que el MEF valida la información financiera al fin de cada mes efectúa las transferencias correspondientes a la cuenta del Banco Central del Ecuador

d. Se procede al registro de devengo, como principio contable y el ingreso correspondiente.

Figura 2. Transferencias desde el MEF

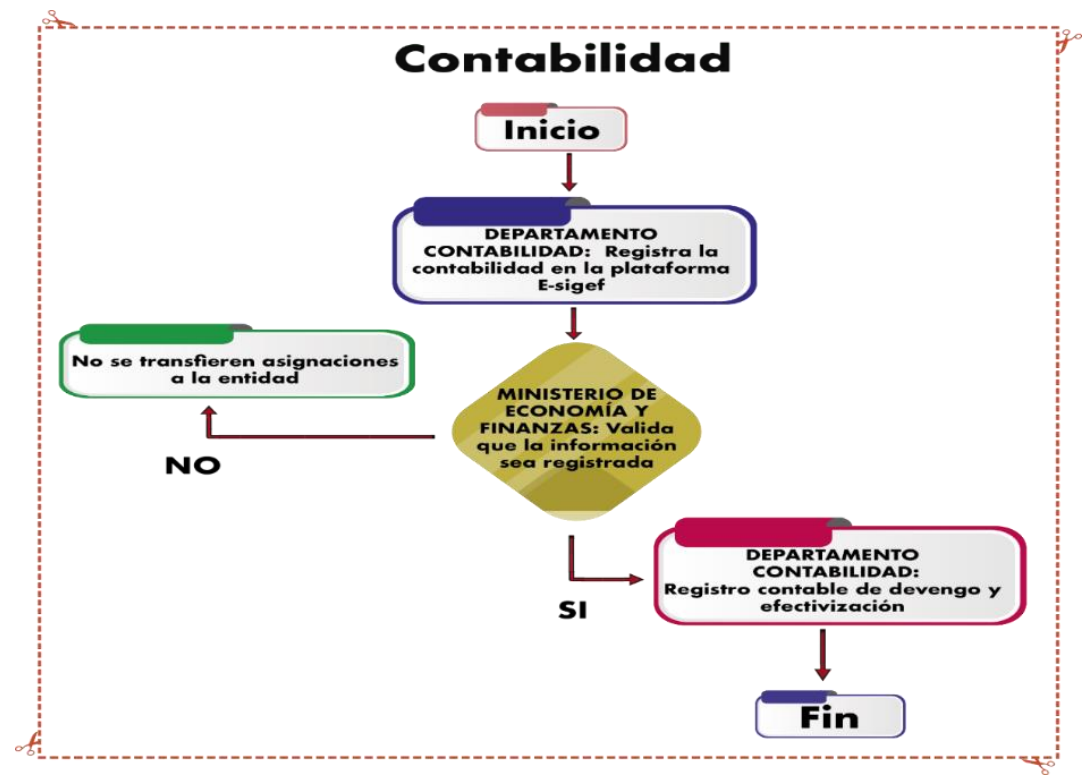


Tabla 2. Transferencias del Gobierno Central, Devengado

\begin{tabular}{|c|c|c|c|c|c|c|}
\hline \multirow[b]{2}{*}{ Cuenta } & \multirow[b]{2}{*}{ Denominación } & \multirow[b]{2}{*}{ Debe } & \multirow[b]{2}{*}{ Haber } & \multicolumn{3}{|c|}{ Ejecución Presupuestaria } \\
\hline & & & & Código & Partida & Devengado \\
\hline 1.1 .3 .18 .06 & $\begin{array}{l}\text { Aportes a juntas } \\
\text { parroquiales }\end{array}$ & 5278.49 & & & & \\
\hline 6.2.6.06.08 & $\begin{array}{l}\text { Aportes a juntas } \\
\text { parroquiales }\end{array}$ & & 5278.49 & 18.06 .08 & $\begin{array}{l}\text { Aportes a } \\
\text { juntas } \\
\text { parroquiales } \\
\text { rurales }\end{array}$ & 5278.49 \\
\hline 1.1 .3 .28 .06 & $\begin{array}{l}\text { Aportes a juntas } \\
\text { parroquiales }\end{array}$ & 7014.23 & & & & \\
\hline 6.2.6.26.08 & $\begin{array}{l}\text { Aportes a juntas } \\
\text { parroquiales }\end{array}$ & & 7014.23 & 28.06 .08 & $\begin{array}{l}\text { Aportes a } \\
\text { juntas } \\
\text { parroquiales } \\
\text { rurales }\end{array}$ & 7014.23 \\
\hline
\end{tabular}

Tabla 3. Transferencias Del Gobierno Central, Ejecutado

\begin{tabular}{|c|c|c|c|c|c|c|}
\hline \multirow[b]{2}{*}{ Cuenta } & \multirow[b]{2}{*}{ Denominación } & \multirow[b]{2}{*}{ Debe } & \multirow[b]{2}{*}{ Haber } & \multicolumn{3}{|c|}{ Ejecución Presupuestaria } \\
\hline & & & & Código & Partida & Ejecutado \\
\hline 1.1 .1 .03 .01 & $\begin{array}{c}\text { Banco Central Del } \\
\text { Ecuador }\end{array}$ & 12292.72 & & & & \\
\hline 1.1.3.18.06 & $\begin{array}{l}\text { Aportes A Juntas } \\
\text { Parroquiales } \\
\text { (Corriente) }\end{array}$ & & 5278.49 & 18.06 .08 & $\begin{array}{l}\text { Aportes A } \\
\text { Juntas } \\
\text { Parroquiales } \\
\text { Rurales }\end{array}$ & 5278.49 \\
\hline 1.1.3.28.06 & $\begin{array}{l}\text { Aportes A Juntas } \\
\text { Parroquiales } \\
\text { (Inversión) }\end{array}$ & & 7014.23 & 28.06 .08 & $\begin{array}{l}\text { Aportes A } \\
\text { Juntas } \\
\text { Parroquiales } \\
\text { Rurales }\end{array}$ & 7014.23 \\
\hline
\end{tabular}

Tabla 4. Consideraciones Normas técnicas y NISCP

\section{Consideraciones Normas técnicas de Consideraciones NICSP \\ Contabilidad gubernamental}

- Consideración para ver si es un activo de la

Control financiero: Montos asignados para la entidad en cuenta preestablecida

Control administrativo: Documentos de soporte de la transacción. entidad y si pertenece a activo corriente $o$ no corriente.

- Utilizar un manual de cuentas uniforme a nivel mundial, aunque la misma NICSP 1 en su párrafo 8 señala que se pueden utilizar detalles representativos, siempre que no se cree confusiones en cada uno de los usuarios.

- Se considera el devengado.

\section{Fuente: NICSP 1}




\section{Procedimiento para registro y control de anticipos de fondos: anticipo de sueldos.}

Se debe considerar lo siguiente:

- La máxima autoridad recibe la petición formal por parte del funcionario.

- Se revisa que se cumpla con todos los requisitos y se constata que se encuentre dentro de los límites establecidos por la ley y que el periodo a descontar se encuentre dentro del rango permitido.

- Se notifica la autorización del anticipo

- Se registra en contabilidad el hecho económico

- Se transfiere los fondos a la cuenta del empleado

- Se descuenta mensualmente del rol de pagos

Figura 3. Anticipo de sueldos

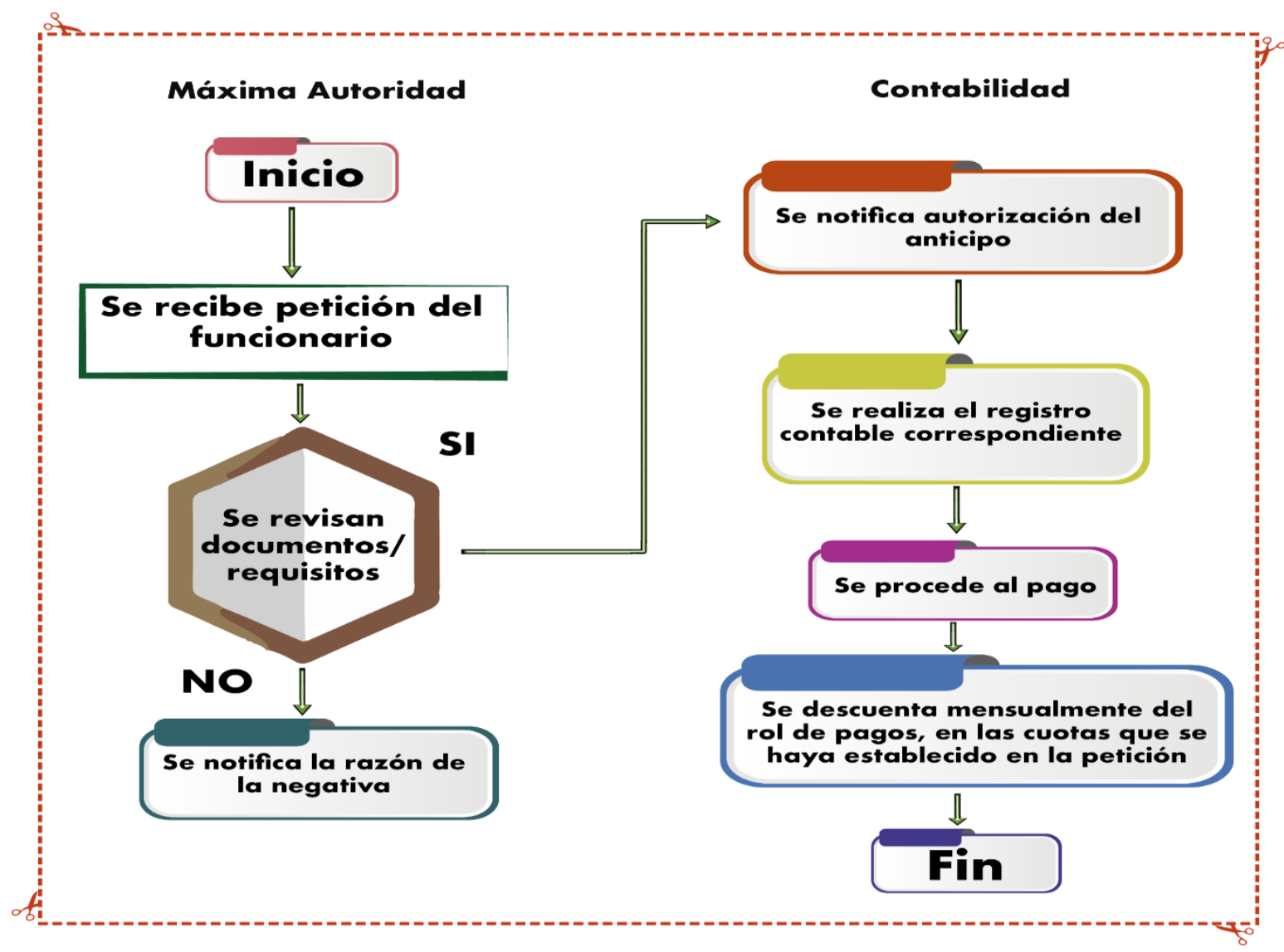


Tabla 5. Anticipo de fondos, asiento que registra la generación del anticipo

\begin{tabular}{|c|c|c|c|c|c|c|}
\hline \multirow[b]{2}{*}{ Cuenta } & \multirow[b]{2}{*}{ Denominación } & \multirow[b]{2}{*}{ Debe } & \multirow[b]{2}{*}{ Haber } & \multicolumn{3}{|c|}{ Ejecución Presupuestaria } \\
\hline & & & & Código & Partida & Devengado \\
\hline 1.1.2.01.03 & $\begin{array}{l}\text { Anticipo de } \\
\text { remuneraciones }\end{array}$ & 400.0 & & & & \\
\hline 1.1.1.03.01 & $\begin{array}{l}\text { Banco Central del } \\
\text { Ecuador }\end{array}$ & & 400.00 & & & \\
\hline
\end{tabular}

Tabla 6. Anticipos de fondos, devengado

\begin{tabular}{|c|c|c|c|c|c|c|}
\hline \multirow{2}{*}{ Cuenta } & \multirow{2}{*}{ Denominación } & \multirow{2}{*}{ Debe } & \multirow{2}{*}{ Haber } & \multicolumn{3}{|c|}{ Ejecución Presupuestaria } \\
\hline & & & & Código & Partida & Devengado \\
\hline 6.3.3.01.05 & $\begin{array}{l}\text { Remuneraciones } \\
\text { Unificadas }\end{array}$ & 675.00 & & 51.01 .05 & $\begin{array}{l}\text { Remuneraciones } \\
\text { Unificadas }\end{array}$ & 675.00 \\
\hline 2.1.3.51.01.005 & $\begin{array}{l}\text { Remuneraciones } \\
\text { Unificadas }\end{array}$ & & 275.00 & & & \\
\hline 2.1.3.51.99.004 & $\begin{array}{l}\text { Anticipo de } \\
\text { Remuneraciones }\end{array}$ & & 400.00 & & & \\
\hline
\end{tabular}

Tabla 7. Anticipos de fondos, ejecutado

\begin{tabular}{|c|c|c|c|c|c|c|}
\hline \multirow[b]{2}{*}{ Cuenta } & \multirow[b]{2}{*}{ Denominación } & \multirow[b]{2}{*}{ Debe } & \multirow[b]{2}{*}{ Haber } & \multicolumn{3}{|c|}{ Ejecución Presupuestaria } \\
\hline & & & & Código & Partida & Ejecutado \\
\hline 2.1 .3 .51 .01 .005 & $\begin{array}{l}\text { Remuneraciones } \\
\text { Unificadas }\end{array}$ & 275.00 & & 51.01 .05 & $\begin{array}{l}\text { Remuneraciones } \\
\text { Unificadas }\end{array}$ & 275.00 \\
\hline 2.1 .3 .51 .99 .004 & $\begin{array}{l}\text { Anticipo de } \\
\text { Remuneraciones }\end{array}$ & 400.00 & & 51.01 .05 & $\begin{array}{l}\text { Remuneraciones } \\
\text { Unificadas }\end{array}$ & 400.00 \\
\hline 1.1.2.01.03 & $\begin{array}{l}\text { Anticipo de } \\
\text { remuneraciones }\end{array}$ & & 400.00 & & & \\
\hline 1.1 .1 .03 .01 & $\begin{array}{l}\text { Banco Central del } \\
\text { Ecuador }\end{array}$ & & 275.00 & & & \\
\hline
\end{tabular}

Tabla 8. Consideraciones Normas técnicas y NISCP

\section{Consideraciones Normas técnicas de \\ Consideraciones NICSP Contabilidad gubernamental}

Control financiero: valores depositados en cuenta del empleado

Control administrativo: documentos de petición, autorización y transferencia
- Utilizar el devengado como principio de la contabilidad en el sector publico

- Determinar las cuentas de anticipo como parte del activo corriente, ya que se harán efectivos en menos de doce meses o dentro del ciclo contable del cual se informa en los estados financieros

- Considerar las disposiciones de actualizar la información contable con base a NICSP en todas las organizaciones no financieras del sector público.

\section{Fuente: NICSP 1}




\section{Procedimiento para registro y control de bienes de administración: adquisición.}

Se debe considerar:

- Análisis de necesidad en la entidad

- Certificación presupuestaria

- Existencia en el Plan Anual de Contrataciones

- Verificación de disponibilidad en catalogo electrónico

- Autorización de la adquisición

- Determinación del proceso de contratación pública

- Recepción de bienes

- Autorización del pago

- Registro contable

- Registro del pago SPI

Figura 4. Flujograma de adquisiciones

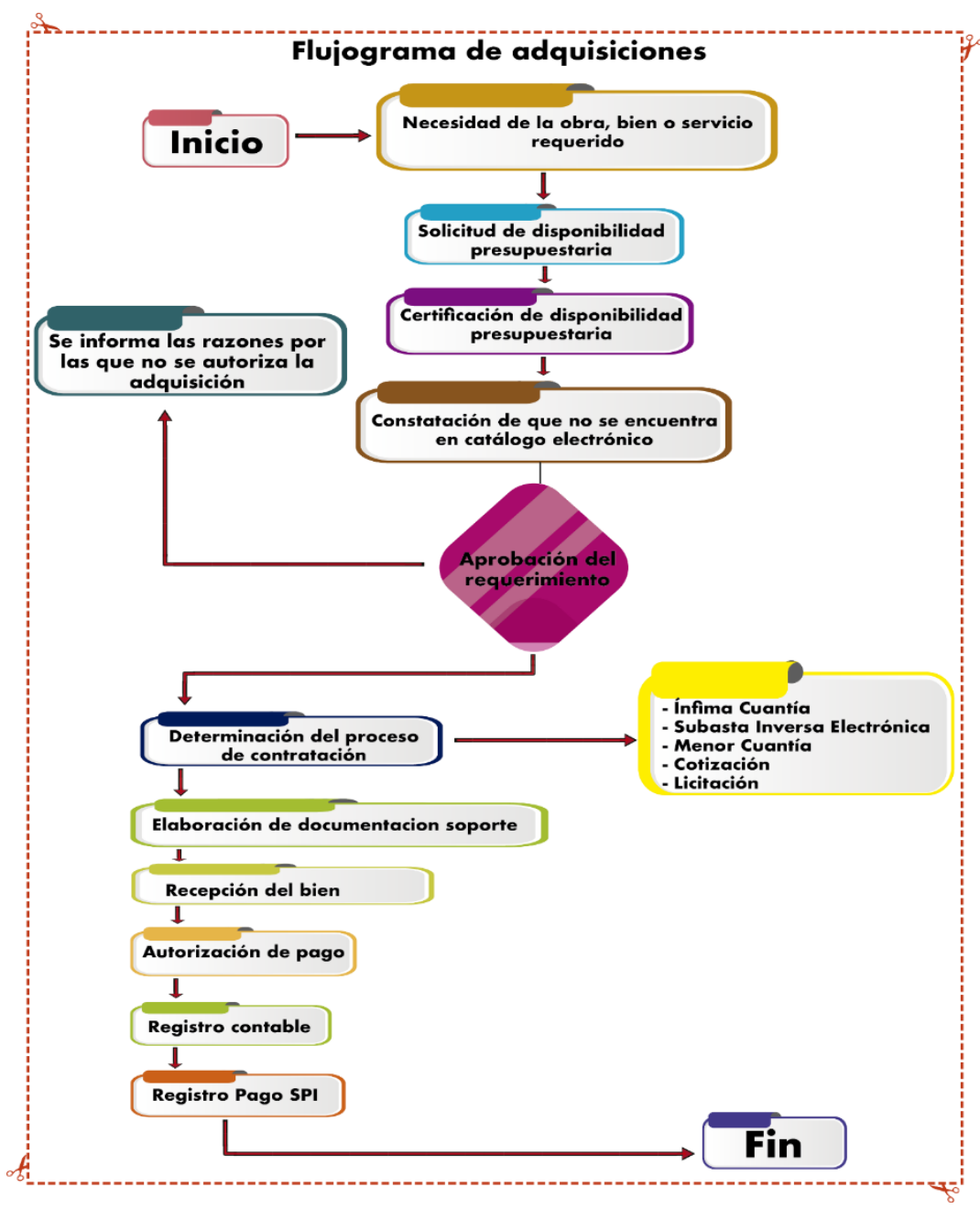


Tabla 9. Adquisición de bienes de administración, devengado

\begin{tabular}{|c|c|c|c|c|c|c|}
\hline \multirow[b]{2}{*}{ Cuenta } & \multirow[b]{2}{*}{ Denominación } & \multirow[b]{2}{*}{ Debe } & \multirow[b]{2}{*}{ Haber } & \multicolumn{3}{|c|}{ Ejecución Presupuestaria } \\
\hline & & & & Código & Partida & Devengado \\
\hline 141.01 .03 & Mobiliarios & 2023.00 & & 84.01 .03 & Mobiliarios & 2023.00 \\
\hline 213.84 .01 & $\begin{array}{l}\text { C por Pagar Inver. } \\
\text { Bienes de Larga } \\
\text { Duración - Proveedor }\end{array}$ & & 1710.01 & & & \\
\hline 213.84 .02 & $\begin{array}{l}\text { C por Pagar Inver. } \\
\text { Bienes de Larga } \\
\text { Duración - Renta }\end{array}$ & & 20.23 & & & \\
\hline 213.84 .03 & $\begin{array}{l}\text { C por Pagar Inver. } \\
\text { Bienes de Larga } \\
\text { Duración }-70 \% \\
\text { Proveedor }\end{array}$ & & 169.93 & & & \\
\hline 213.84 .05 & $\begin{array}{l}\text { C por Pagar Inver. } \\
\text { Bienes de Larga } \\
\text { Duración - 30\% SRI }\end{array}$ & & 122.83 & & & \\
\hline
\end{tabular}

Tabla 10. Adquisición de bienes de administración, ejecutado

\begin{tabular}{|c|c|c|c|c|c|c|}
\hline \multirow[b]{2}{*}{ Cuenta } & \multirow[b]{2}{*}{ Denominación } & \multirow[b]{2}{*}{ Debe } & \multirow[b]{2}{*}{ Haber } & \multicolumn{3}{|c|}{ Ejecución Presupuestaria } \\
\hline & & & & Código & Partida & Ejecutado \\
\hline 213.84 .01 & $\begin{array}{l}\text { C por Pagar Inver. } \\
\text { Bienes de Larga } \\
\text { Duración - Proveedor }\end{array}$ & 1710.01 & & 84.01 .03 & Mobiliarios & 1710.01 \\
\hline 213.84 .02 & $\begin{array}{l}\text { C por Pagar Inver. } \\
\text { Bienes de Larga } \\
\text { Duración - Renta }\end{array}$ & 20.23 & & 84.01 .03 & Mobiliarios & 20.23 \\
\hline 213.84 .03 & $\begin{array}{l}\text { C por Pagar Inver. } \\
\text { Bienes de Larga } \\
\text { Duración }-70 \% \\
\text { Proveedor }\end{array}$ & 169.93 & & 84.01 .03 & Mobiliarios & 169.93 \\
\hline 213.84 .05 & $\begin{array}{l}\text { C por Pagar Inver. } \\
\text { Bienes de Larga } \\
\text { Duración }-30 \% \text { SRI }\end{array}$ & 122.83 & & 84.01 .03 & Mobiliarios & 122.83 \\
\hline 2.1.2.01.03 & $\begin{array}{l}\text { C por Pagar } \\
\text { Retenciones SRI }\end{array}$ & & 20.23 & & & \\
\hline 2.1.2.81.02 & $\begin{array}{l}\text { C por Pagar } \\
\text { Retención de IVA } \\
300 \%\end{array}$ & & 122.83 & & & \\
\hline 1.1 .1 .03 .01 & $\begin{array}{l}\text { Banco Central del } \\
\text { Ecuador }\end{array}$ & & 1879.94 & & & \\
\hline
\end{tabular}


Tabla 11. Consideraciones Normas técnicas y NISCP

Consideraciones Normas técnicas de

Consideraciones NICSP

Contabilidad gubernamental

Control financiero: valores cancelados por la entidad, proformas

Control administrativo: adquisiciones utilizando las herramientas del portal de compras públicas / documentos de respaldo
- Utilizar el devengado como principio de la contabilidad en el sector publico

- Analizar las consideraciones de la NICSP 17 Propiedad planta y equipo para el reconocimiento, que manifiesta lo siguiente en su párrafo 12 .

Son activos tangibles los que:

$\checkmark \quad$ Son parte de la institución si su uso es exclusivo para las actividades que enmarcan la razón de ser de cada entidad; y

$\checkmark$ De los cuales se espera recibir beneficios por más de un ejercicio económico.

- Determinar su vida útil y valor de salvamento

\section{Fuente: NICSP}

\section{Procedimiento para registro y control de deudores financieros.}

Se debe considerar

- Análisis de cuentas por cobrar que pasan de un período a otro, respaldados en las disposiciones legales

- Registro contable para dar cumplimiento de los dispuesto en la normativa

Figura 5. Flujograma, deudores financieros.

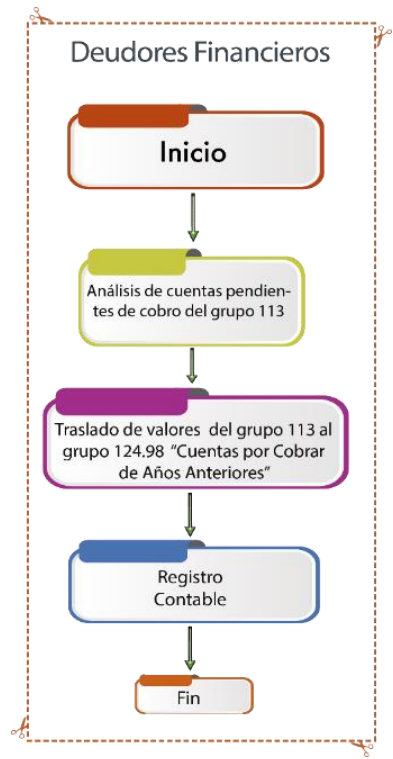


Tabla 12. Deudores financieros, origen de las cuentas

\begin{tabular}{|c|c|c|c|c|c|c|}
\hline \multirow[b]{2}{*}{ Cuenta } & \multirow[b]{2}{*}{ Denominación } & \multirow[b]{2}{*}{ Debe } & \multirow[b]{2}{*}{ Haber } & \multicolumn{3}{|c|}{ Ejecución Presupuestaria } \\
\hline & & & & Código & Partida & Devengado \\
\hline 1.2 .4 .98 .01 & $\begin{array}{c}\text { C X C años } \\
\text { anteriores - } \\
\text { Gobierno Central }\end{array}$ & 12292.7 & & & & \\
\hline 1.1.3.18.06 & $\begin{array}{l}\text { Aportes a juntas } \\
\text { parroquiales }\end{array}$ & & 5278.49 & & & \\
\hline 1.1.3.28.06 & $\begin{array}{l}\text { Aportes a juntas } \\
\text { parroquiales }\end{array}$ & & 7014.23 & & & \\
\hline
\end{tabular}

Tabla 13. Deudores financieros, devengado, año siguiente

\begin{tabular}{|c|c|c|c|c|c|c|}
\hline \multirow[b]{2}{*}{ Cuenta } & \multirow[b]{2}{*}{ Denominación } & \multirow[b]{2}{*}{ Debe } & \multirow[b]{2}{*}{ Haber } & \multicolumn{3}{|c|}{ Ejecución Presupuestaria } \\
\hline & & & & Código & Partida & Devengado \\
\hline 1.1 .3 .98 .01 & $\begin{array}{l}\mathrm{CX} \text { X años } \\
\text { anteriores - } \\
\text { Gobierno Central }\end{array}$ & 12292.72 & & & & \\
\hline 1.2.4.98.01 & $\begin{array}{l}\text { C X C años } \\
\text { anteriores - } \\
\text { Gobierno Central }\end{array}$ & & 12292.72 & 3.8.01.01 & $\begin{array}{l}\text { De cuentas } \\
\text { pendientes por } \\
\text { cobrar }\end{array}$ & 12292.72 \\
\hline
\end{tabular}

Tabla 14. Deudores financieros, devengado, año siguiente

\begin{tabular}{|c|c|c|c|c|c|c|}
\hline \multirow[b]{2}{*}{ Cuenta } & \multirow[b]{2}{*}{ Denominación } & \multirow[b]{2}{*}{ Debe } & \multirow[b]{2}{*}{ Haber } & \multicolumn{3}{|c|}{ Ejecución Presupuestaria } \\
\hline & & & & Código & Partida & Ejecutado \\
\hline 1.1.1.03.01 & $\begin{array}{c}\text { Banco Central del } \\
\text { Ecuador }\end{array}$ & 12292.72 & & & & \\
\hline 1.1.3.98.01 & $\begin{array}{l}\text { C X C años } \\
\text { anteriores - } \\
\text { Gobierno Central }\end{array}$ & & 12292.72 & 3.8.01.01 & $\begin{array}{l}\text { De cuentas } \\
\text { pendientes } \\
\text { por cobrar }\end{array}$ & 12292.72 \\
\hline
\end{tabular}


Tabla 15. Consideraciones Normas técnicas y NISCP

Consideraciones Normas técnicas de Consideraciones NICSP Contabilidad gubernamental

\begin{tabular}{|c|c|c|}
\hline $\begin{array}{l}\text { Control administrativo y financiero Al } \\
\text { finalizar el periodo contable cada año el } \\
\text { Ministerio de Economía y finanzas Públicas } \\
\text { emite una resolución donde se establecen las } \\
\text { directrices presupuestarias que son de } \\
\text { cumplimiento obligatorio para las entidades que } \\
\text { conforman el ámbito del Presupuesto General del } \\
\text { Estado, de esta manera un apartado menciona } \\
\text { que: "Los saldos al } 31 \text { de diciembre de las } \\
\text { cuentas del grupo } 113 \text { "Cuentas por Cobrar" } \\
\text { serán trasladados a las cuentas correspondientes } \\
\text { de la cuenta } 124.98 \text { "Cuentas por Cobrar de Años } \\
\text { Anteriores": }\end{array}$ & - & 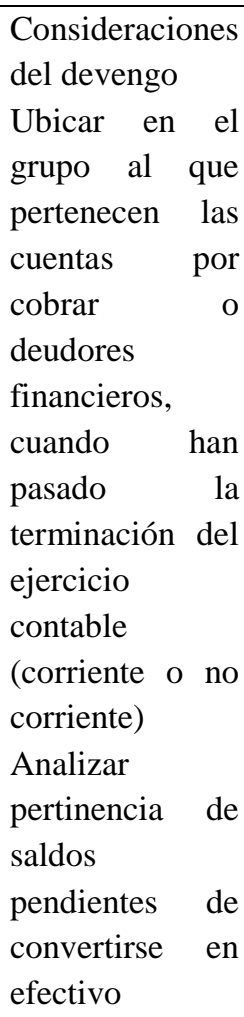 \\
\hline
\end{tabular}

\section{Fuente: NICSP}

\section{Procedimiento para registro y control de inversiones diferidas, Pólizas de caución.}

Se debe considerar lo siguiente:

- Análisis de necesidad de contar con seguros

- Constatar que se encuentre en el Plan Anual de contrataciones

- Aprobación por parte de la máxima autoridad, para la contratación de seguros, ya sea por subasta inversa o ínfima cuantía.

- Registro contable de contratación de seguros

- Pago a proveedores

- Al final del periodo se determina el tiempo de uso del seguro para registrar el asiento del gasto seguros correspondientes al periodo económico. 
Figura 6. Flujograma inversiones diferidas

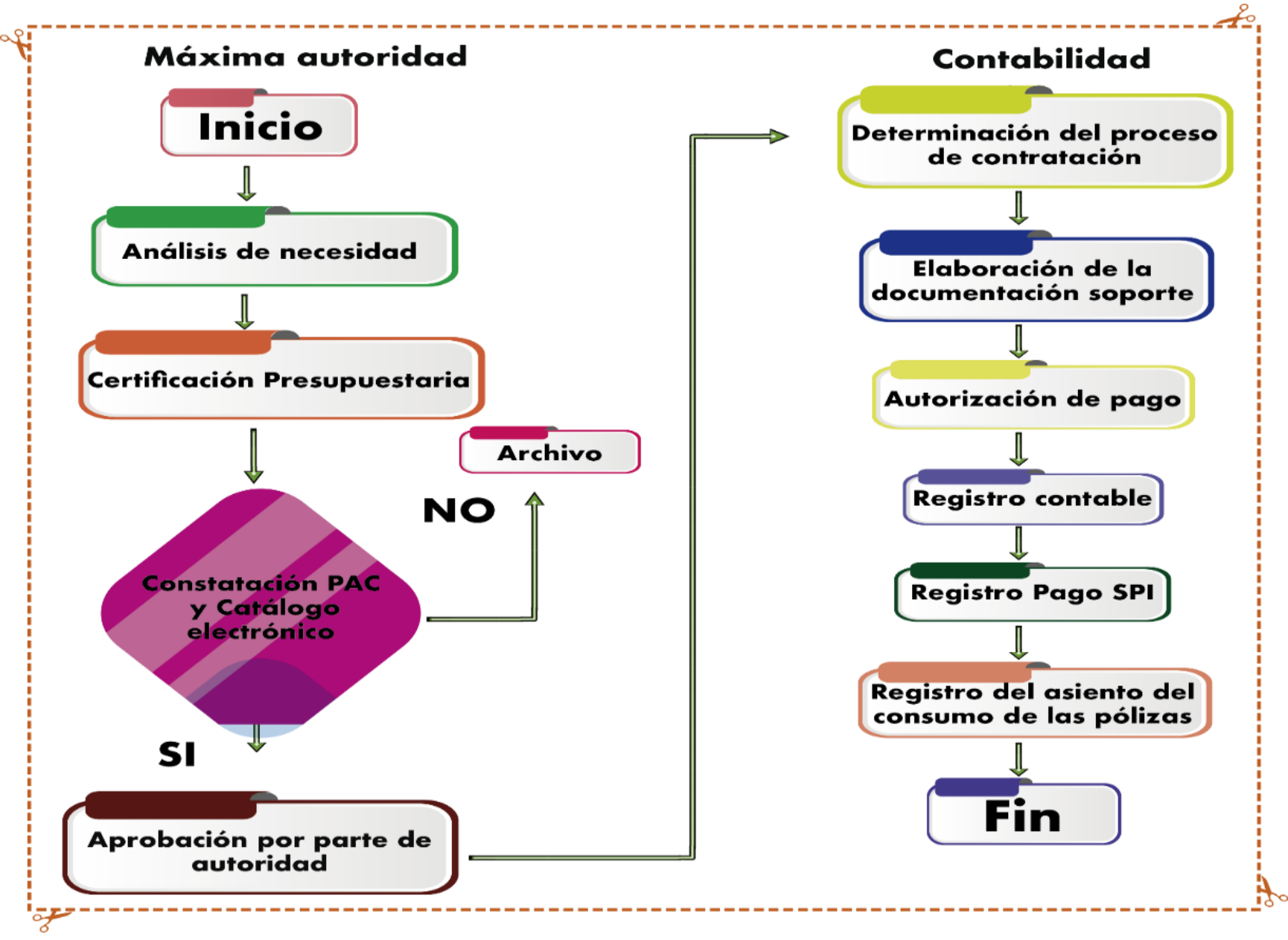

Tabla 16. Inversiones diferidas, compra de pólizas de caución, devengado

\begin{tabular}{clccccc}
\hline \multirow{2}{*}{ Cuenta } & \multirow{2}{*}{ Denominación } & Debe & Haber & Código & Partida & Devengado \\
\hline 1.2.5.31.01 & $\begin{array}{l}\text { Prepago de } \\
\text { Seguros }\end{array}$ & 1075.82 & & 5.7 .02 .01 & Seguros & 1075.82 \\
$\begin{array}{l}\text { C por pagar otros } \\
\text { gastos }\end{array}$ & & 1075.82 & & & \\
\hline
\end{tabular}

Tabla 17. Inversiones diferidas, compra de pólizas de caución, ejecutado

\begin{tabular}{clccccc}
\hline & & & \multicolumn{3}{c}{ Ejecución Presupuestaria } \\
Cuenta & Denominación & Debe & Haber & Código & Partida & Ejecutado \\
\hline 2.1 .3 .57 .01 & $\begin{array}{l}\text { C por pagar otros } \\
\text { gastos }\end{array}$ & 1075.82 & & 5.7 .02 .01 & Seguros & 1075.82 \\
1.1.1.03.01 & & & & & \\
& $\begin{array}{l}\text { Banco Central del } \\
\text { Ecuador }\end{array}$ & & 1075.82 & & & \\
\hline
\end{tabular}


Tabla 18. Contabilización del ajuste a diferidos al 31 de diciembre

\begin{tabular}{|c|c|c|c|c|c|c|}
\hline \multirow[b]{2}{*}{ Cuenta } & \multirow[b]{2}{*}{ Denominación } & \multirow[b]{2}{*}{ Debe } & \multirow[b]{2}{*}{ Haber } & \multicolumn{3}{|c|}{ Ejecución Presupuestaria } \\
\hline & & & & Código & Partida & Ejecutado \\
\hline 6.3 .5 .04 .01 & Seguros & 358.61 & & & & \\
\hline 1.2.5.31.01 & Prepagos seguros & & 358.61 & & & \\
\hline
\end{tabular}

Tabla 19. Consideraciones Normas técnicas y NISCP

\section{Consideraciones Normas técnicas de Consideraciones NICSP Contabilidad gubernamental}

Control administrativo y financiero $\mathrm{Al}$ cierre de cada ejercicio económico se debe considerar el consumo de los seguros preparados, el valor registrado en la cuenta 6.3.5.04.01 se prorratea para el numero de meses que han transcurrido desde la adquisición de las pólizas de caución, por lo que la contabilización queda sin afectación presupuestaria de la siguiente manera:

- $\quad$ Registrar los hechos económicos en el ciclo contable en que ocurren, es decir registrar la parte proporcional de los gastos ya utilizados por la entidad.

\section{Fuente: NICSP}

\section{Procedimiento para registro y control de inversiones en obras en proceso:}

Se debe considerar lo siguiente:

- Necesidad o requerimiento

- Certificación presupuestaria

- Analizar que se encuentre dentro del PAC

- Determinar el proceso de contratación

- Actas de entrega recepción

- Liquidación económica 
Figura 7. Flujograma obras en proceso

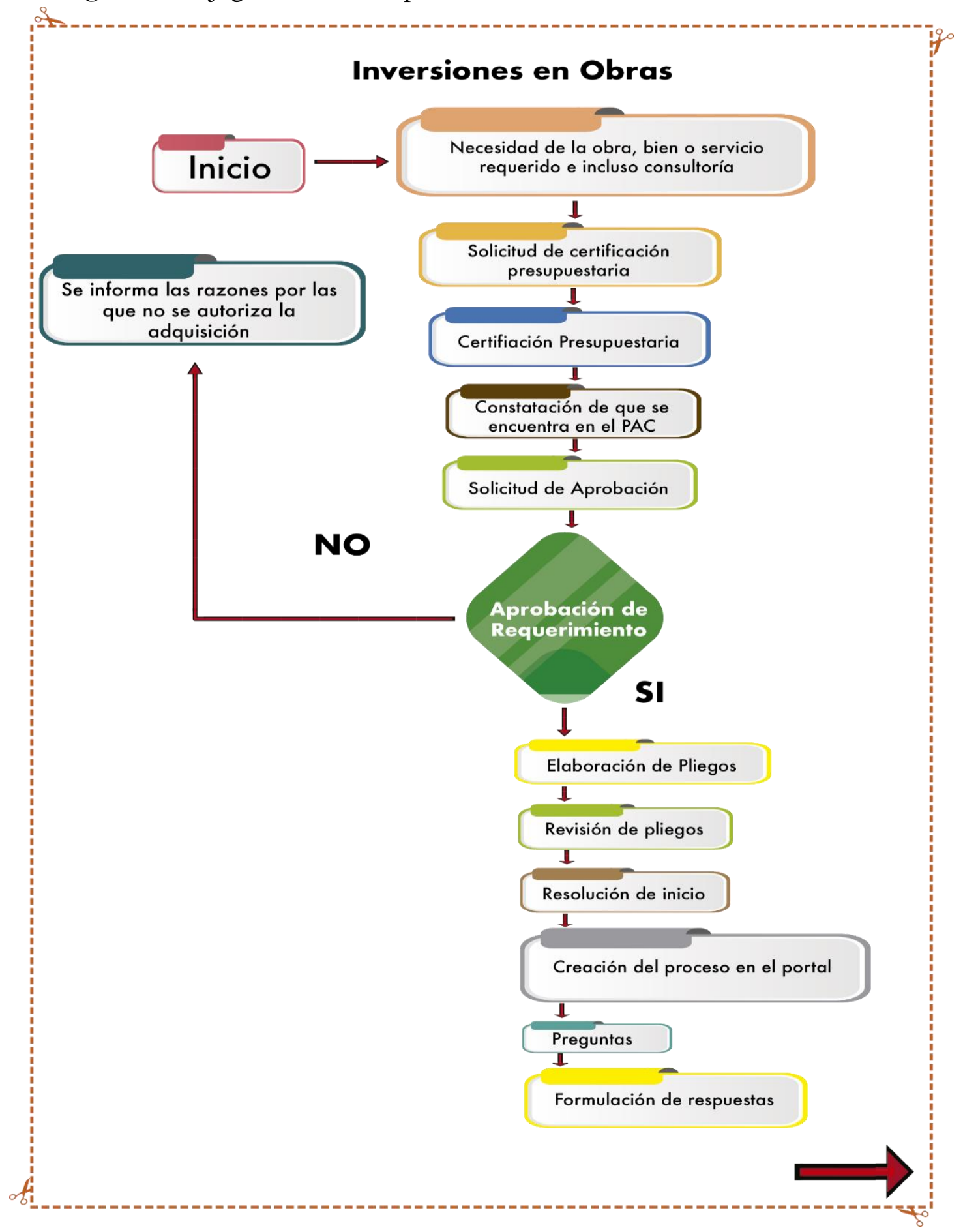


Figura 8. Flujograma obras en proceso

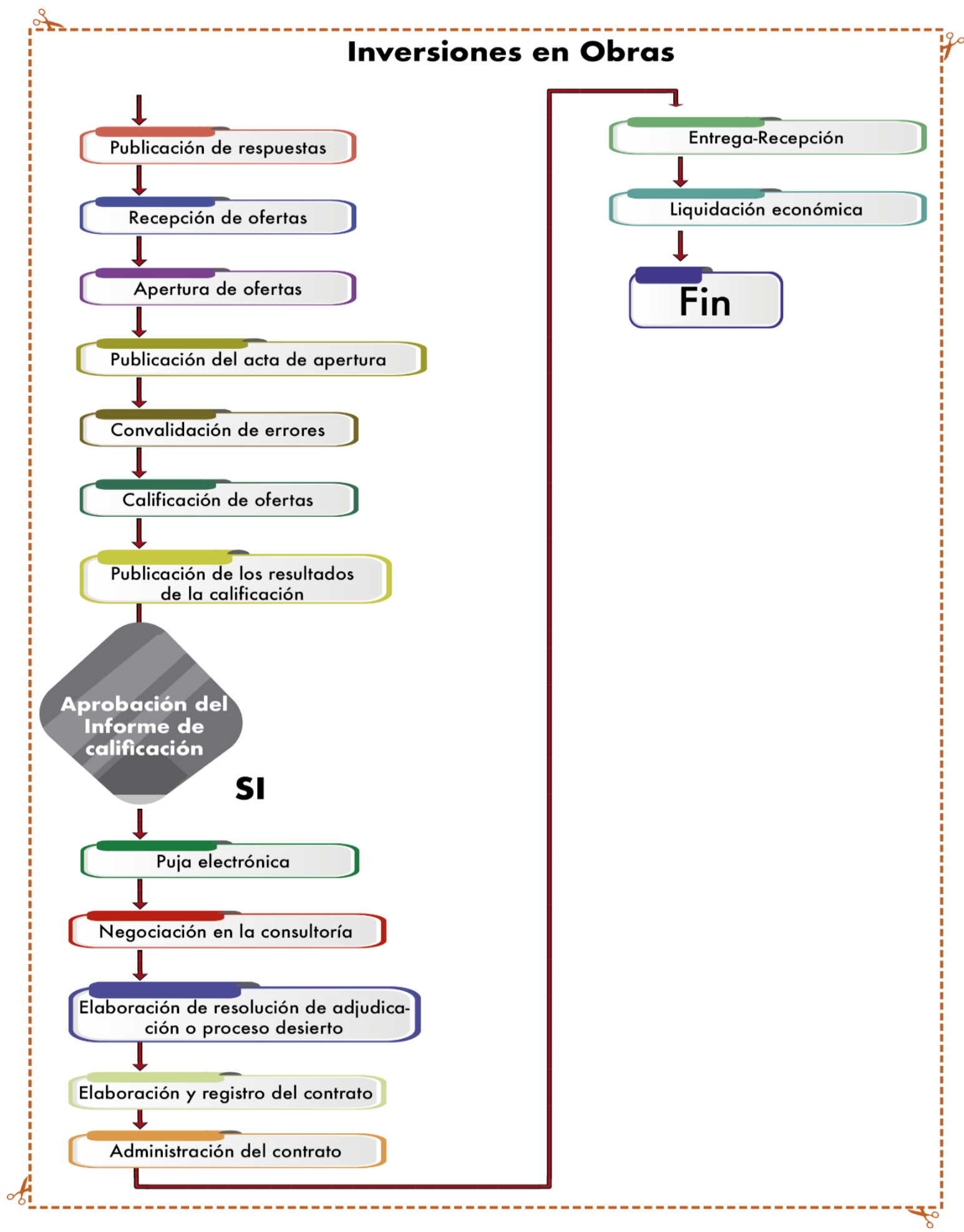


Tabla 20. Obras en proceso, devengado

\begin{tabular}{|c|c|c|c|c|c|c|}
\hline \multirow[b]{2}{*}{ Cuenta } & \multirow[b]{2}{*}{ Denominación } & \multirow[b]{2}{*}{ Debe } & \multirow[b]{2}{*}{ Haber } & \multicolumn{3}{|c|}{ Ejecución Presupuestaria } \\
\hline & & & & Código & Partida & Devengado \\
\hline 1.5.1.51.04 & $\begin{array}{l}\text { De Urbanización y } \\
\text { embellecimiento }\end{array}$ & 74931.42 & & 7.5 .01 .04 & $\begin{array}{l}\text { De Urbanización } \\
\text { y } \\
\text { embellecimiento }\end{array}$ & 74931.42 \\
\hline 213.75 .01 & $\begin{array}{l}\text { C por pagar Inver. } \\
\text { Bienes de Larga } \\
\text { Duración - } \\
\text { Proveedor }\end{array}$ & & 66234.02 & & & \\
\hline 213.75 .02 & $\begin{array}{l}\text { C por pagar Inver. } \\
\text { Bienes de Larga } \\
\text { Duración - Renta }\end{array}$ & & 669.03 & & & \\
\hline 213.75 .03 & $\begin{array}{l}\text { C por pagar Inver. } \\
\text { Bienes de Larga } \\
\text { Duración }-70 \% \\
\text { Proveedor }\end{array}$ & & 5619.86 & & & \\
\hline 213.75 .05 & $\begin{array}{l}\text { C por pagar Inver. } \\
\text { Bienes de Larga } \\
\text { Duración }-30 \% \\
\text { SRI }\end{array}$ & & 2408.51 & & & \\
\hline
\end{tabular}

Tabla 21. Obras en proceso, ejecutado

\begin{tabular}{|c|c|c|c|c|c|c|}
\hline \multirow[b]{2}{*}{ Cuenta } & \multirow[b]{2}{*}{ Denominación } & \multirow[b]{2}{*}{ Debe } & \multirow[b]{2}{*}{ Haber } & \multicolumn{3}{|c|}{ Ejecución Presupuestaria } \\
\hline & & & & Código & Partida & Ejecutado \\
\hline 213.75 .01 & $\begin{array}{l}\text { C por pagar Inver. } \\
\text { Bienes de Larga } \\
\text { Duración - } \\
\text { Proveedor }\end{array}$ & 66234.02 & & 7.5 .01 .04 & $\begin{array}{l}\text { De Urbanización } \\
\text { y } \\
\text { embellecimiento }\end{array}$ & 66234.02 \\
\hline 213.75 .02 & $\begin{array}{l}\text { C por pagar Inver. } \\
\text { Bienes de Larga } \\
\text { Duración - Renta }\end{array}$ & 669.03 & & 7.5.01.04 & $\begin{array}{l}\text { De Urbanización } \\
\text { y } \\
\text { embellecimiento }\end{array}$ & 669.03 \\
\hline 213.75 .03 & $\begin{array}{l}\text { C por pagar Inver. } \\
\text { Bienes de Larga } \\
\text { Duración }-70 \% \\
\text { Proveedor }\end{array}$ & 5619.86 & & 7.5.01.04 & $\begin{array}{l}\text { De Urbanización } \\
\text { y } \\
\text { embellecimiento }\end{array}$ & 5619.86 \\
\hline 213.75 .05 & $\begin{array}{l}\text { C por pagar Inver. } \\
\text { Bienes de Larga } \\
\text { Duración }-30 \% \\
\text { SRI }\end{array}$ & 2408.51 & & 7.5.01.04 & $\begin{array}{l}\text { De Urbanización } \\
\text { y } \\
\text { embellecimiento }\end{array}$ & 2408.51 \\
\hline 2.1.2.01.03 & $\begin{array}{l}\text { C por pagar } \\
\text { Retenciones SRI }\end{array}$ & & 669.03 & & & \\
\hline 2.1.2.81.02 & $\begin{array}{l}\text { C por pagar } \\
\text { Retención de IVA } \\
300 \%\end{array}$ & & 2408.51 & & & \\
\hline 1.1.1.03.01 & $\begin{array}{l}\text { Banco Central del } \\
\text { Ecuador }\end{array}$ & & 71853.88 & & & \\
\hline
\end{tabular}


Tabla 22. Consideraciones Normas técnicas y NISCP

\begin{tabular}{ll}
\hline $\begin{array}{c}\text { Consideraciones Normas técnicas de } \\
\text { Contabilidad gubernamental }\end{array}$ & Consideraciones NICSP \\
\hline Control administrativo y financiero que & Determinar a \\
se encuentre en el presupuesto aprobado & qué grupo de \\
y se realicen los procesos de & activo \\
contratación que mejor beneficien a la & pertenecen en \\
entidad. & virtud a sus \\
& características \\
& - Revisar su \\
& costo, que se \\
& verificable \\
\hline
\end{tabular}

\section{Fuente: NICSP}

\section{Conclusiones.}

- La preparación de los estados financieros a partir de las NICSP permite a los usuarios disponer de información que valore la responsabilidad de la gestión de todos los recursos que la entidad pública controla y administra, además, admite valorar su posición financiera, desempeño financiero, flujos de efectivo y tomar decisiones en base a los reportes obtenidos.

- Los procedimientos de los activos permiten mejorar el control interno y proporcionan información comprensiva, comparable y razonable acerca de los recursos gestionados y administrados por el ente público.

- En el diagnóstico realizado del GADPF se presentaron falencias en cuanto a la mala utilización de las cuentas y partidas contables, deficiente registro contable relacionado con el principio de devengo, y descuadre del Estado de Flujo del Efectivo reportado al organismo de control, lo que conllevo a determinar las deficiencias con que se maneja la información contable y los riesgos de tomar decisiones con dicha información.

- Los procedimientos contables para el grupo de activo que se proponen al GADPF permitirá reflejar con total transparencia el manejo financiero de la institución, además, agregará valor a las decisiones tomadas por la junta parroquial, ya que las mismas estarán acordes con la realidad institucional.

\section{Referencias bibliográficas}

Ablan Bortone, N. C. (2013). Las Normas Internacionales de Contabilidad para el Sector Público. 223, 224, 225.

Aguirre Ormachea, J. (2010). Nueva Contabilidad General. Madrid: Grafillés. 
Arellano, R. (2012). Diseño de Manuales Administrativos. Editorial Académica Española.

Bravo Valdivieso, M. (2011). Contabilidad General. Quito: Escobar.

Contraloría General del Estado. (2002). Ley Orgánica de la Contraloría General del Estado

Chávez Cruz, G., Campuzano Vásquez, J., \& Alvarado Avilés, F. (2015). Contabiilidad Intermedia. Machala: UTMACH. Obtenido de http://repositorio.utmachala.edu.ec/handle/48000/6743.

Díaz Becerra, O. A. (2010). Estado actual de la aplicación de las NIIF en la preparación de Estados financieros de las empresas peruanas. Contabilidad y Negocios, 8. Obtenido de http://www.redalyc.org/articulo.oa?id=281621783002.

Lamanttina, O. E. (2012). Diseño de planes de cuenta. 11.

Medina Castillo, W., y Morocho Román, Z. (2015). Contabilidad Gubernamental I. Machala: Ediciones utmach.

Ministerio de Economía y Finanzas (MEF). (2017). Normativa de Contabilidad Gubernamental ACTUALIZADA (A67).

Montilla, G. (2005). Armonización o estandarización contable internacional. Cali.

Ortíz Anaya, H. (2008). Análisis financiero aplicado. Bogotá: panamericana Formas e Impresos S.A.

Perea M., S. P., Castellanos S., H. A., \& Valderrama B., Y. J. (2016). Estados financieros previsionales como parte integrante de un conjunto completo de Estados financieros en ambiente NIIF. Una propuesta en el marco de la lógica difusa. Actualidad Contable Faces, 116. Obtenido de http://www.redalyc.org/articulo.oa?id=25744733006.

Reinoso, C. V. (2004). El proceso administrativo y su aplicacion en las empresas. 14.

Romero López, J. (2000). Contabilidad Superior. México: Programas Educativos S.A.

Sánchez, J. Y. (2013). La contabilidad pública en américa latina y el devengo en el Ecuador.

Sánchez, J., y Pincay, D. (2013). La Contabilidad Pública en América Latina y el devengo en Ecuador. Analítica, 19-20.

Tombolato, L. M. (2014). La cuenta de inversión de la provincia de Santa Fé en el marco del proceso de armonización con las normas internacionales de contabilidad para el sector público (NICSP). Documentos y aportes en Administración Pública y Gestión Estatal, 185. Obtenido de http://www.redalyc.org/articulo.oa?id=337539189008 
Universidad Nacional de Loja,. (2009). Auditoría para el sector público y empresas privadas.

Zapata Sánchez, P. (2005). Contabilidad General. Mexico: McGraw-Hill.

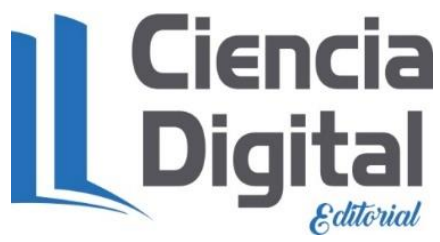




\section{PARA CITAR EL ARTÍCULO INDEXADO.}

Lozano Calero, G., Narváez Zurita, C., Erazo Álvarez, J., \& Montero Cobo, M. (2019). Procedimientos de control y registro contable bajo NIC SP para los activos del Gobierno Autónomo Descentralizado Parroquial de Fundochamba de la provincia de Loja. Visionario Digital, 3(2.1.), 388-419. https://doi.org/10.33262/visionariodigital.v3i2.1.582

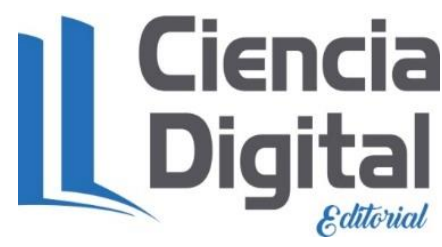

El artículo que se publica es de exclusiva responsabilidad de los autores y no necesariamente reflejan el pensamiento de la Revista Ciencia Digital.

El artículo queda en propiedad de la revista y, por tanto, su publicación parcial y/o total en otro medio tiene que ser autorizado por el director de la Revista Ciencia Digital.
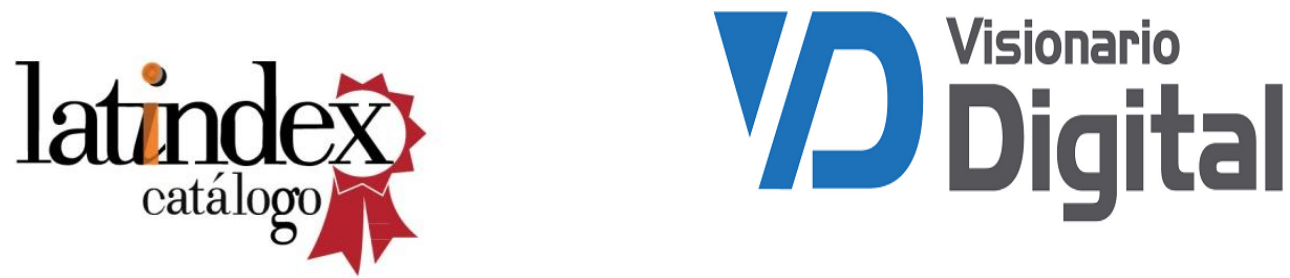